\title{
Massive hemoperitoneum in case of large subserosal fibroid- a rare case report
}

\author{
Yuvrajsingh D. Jadeja*, Radha Shukla, Smruti Vaishnav, Molina Patel
}

Department of Obstetrics and Gynecology, Pramukh Swami Medical College, Karamsad, Anand, Gujarat, India

Received: 09 May 2017

Accepted: 03 June 2017

\section{*Correspondence:}

Dr. Yuvrajsingh D. Jadeja,

E-mail: yuvrajdjadeja@gmail.com

Copyright: (C) the author(s), publisher and licensee Medip Academy. This is an open-access article distributed under the terms of the Creative Commons Attribution Non-Commercial License, which permits unrestricted non-commercial use, distribution, and reproduction in any medium, provided the original work is properly cited.

\begin{abstract}
Rupture of veins on the surface of uterine leiomyoma is an extremely uncommon gynaecological cause of haemoperitoneum. It is a life-threating emergency. In most cases, bleeding is a result of trauma or torsion. Here we report a case of massive intraperitoneal haemorrhage due to rupture of vessels on the surface of large sub-serous leiomyoma to stress on the fact that a differential diagnosis of rupture of surface vessels in a fibroid should be considered while dealing with a case of haemoperitoneum with pelvic masses.
\end{abstract}

Keywords: Fibroid, Haemoperitoneum, Sub serous, Superficial veins

\section{INTRODUCTION}

Uterine fibroid is the most common benign tumour in females of reproductive age group with sub-serous variety being least common and symptomatic. ${ }^{1}$ Common causes of acute abdomen in cases of uterine fibroid include torsion, red degeneration, and torsion of uterus with fibroid or sarcomatous change. ${ }^{2}$ Rupture of superficial vessels of fibroid causing severe intraperitoneal bleed is extremely rare with less than 100 cases reported so far. ${ }^{3-5}$ Here we report a case of large sub-serosal leiomyoma leading to massive haemoperitoneum due to rupture of superficial vein.

\section{CASE REPORT}

A 48-year-old female with previous two live issues presented to emergency care with complain of abdominal pain for six hours, chest pain for ten hours and constipation for one week. Past menstrual history suggested a 25-30 day heavy, painless and regular cycle.
On general examination, patient was conscious, well-built and oriented, with blood pressure of $180 / 110 \mathrm{mmHg}$, tachycardia, grade 2 pallor and maintaining $100 \%$ saturation. Abdominal palpation revealed soft, mildly tender mass in midline of about 22-24-week uterine size with palpable lower margin and intact mobility. On pelvic examination, an anteverted uterus about normal size, with palpable 22-24-week uterine size mass associated with fornicial fullness was appreciated.

On admission, blood panel revealed, haemoglobin of $7.6 \mathrm{~g} / \mathrm{dl}$, total count of 13100 , platelets of 192000 , PT of 16.3, aPTT of 7.4, normal LFT with creatinine of 0.4 , borderline high Ca 125, Trop T of 19.9 and HbA1C of 6.7. Ultrasonography reported uterine size of $8.4 \mathrm{~cm}$ by $5.5 \mathrm{~cm}$ by $4.6 \mathrm{~cm}$, along with a hypoechoic adnexal mass of $12 \mathrm{~cm}$ by $11.7 \mathrm{~cm}$ by $12 \mathrm{~cm}$ (Figure 1 ).

Right ovary was not distinctly seen and left ovarian cyst of $8.2 \mathrm{~cm}$ by $7.6 \mathrm{~cm}$ was noted. She was then posted for abdominal CT to rule out ovarian malignancy. 


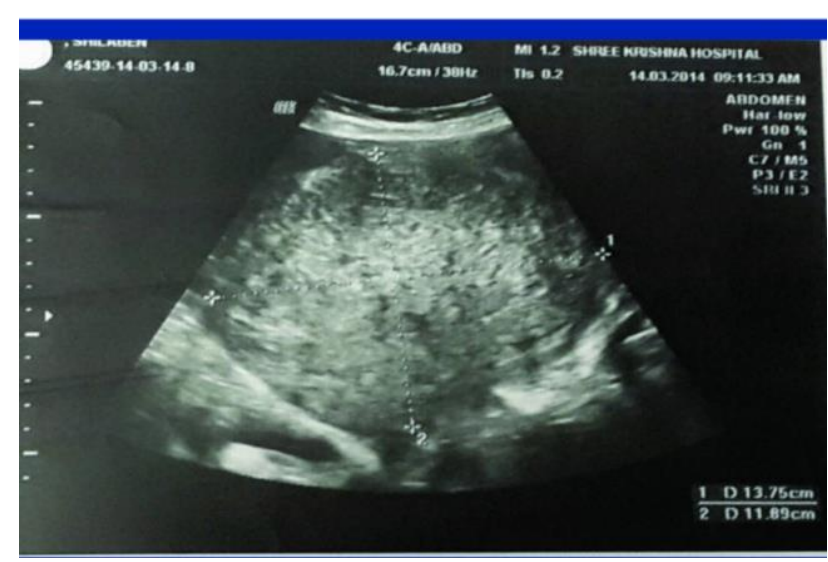

Figure 1: Ultrasonography picture of the fibroid.

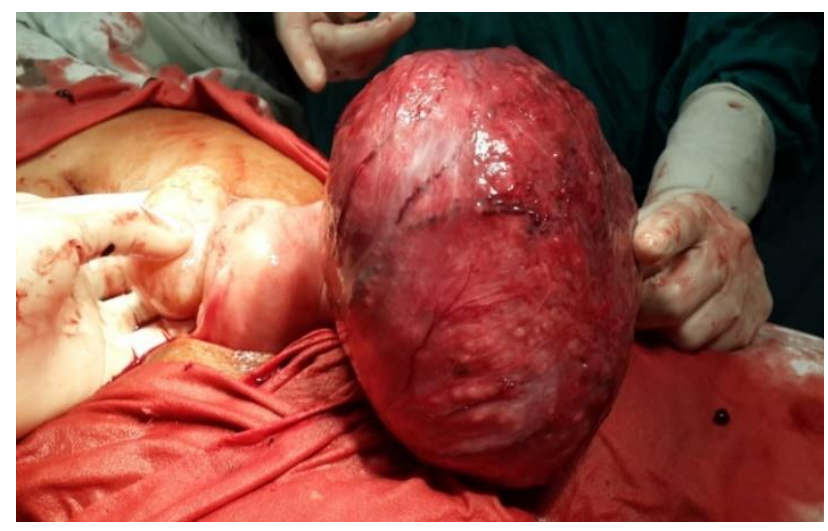

Figure 2: Intraoperative picture showing large subserosal fibroid with normal uterus and ovarian cyst.

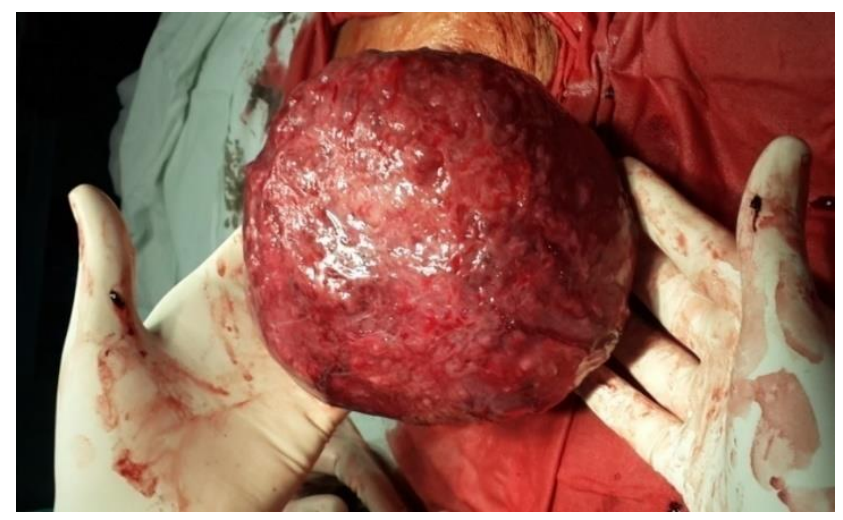

Figure 3: Close-up picture of surface of the fibroid with dilated superficial veins which were bleeding leading to haemoperitoneum

Five hours post admission she developed hypotension associated with 2-3 episodes of vomiting and abdominal tenderness. She was then taken for emergency laparotomy.

Intraoperative, $2 \mathrm{~L}$ of haemoperitoneum was found due to rupture of superficial veins along with partial torsion of uterine fibroid (Figure 2 and 3).
Frozen section was sent. Histopathology report suggested a leiomyoma, and thus pan-hysterectomy was performed. She was then discharged on 4th post-op day.

\section{DISCUSSION}

Uterine fibroid is the commonest benign tumour seen in women of reproductive age group with sub-serous variety being the least common and least symptomatic and are known for some rare complications such as torsion of pedical and detachment from the parent uterus becoming wandering types. ${ }^{6}$ Various causes of acute abdomen with fibroid uterus have been known, but massive haemoperitoneum secondary to spontaneous rupture of a vessel overlying a myoma is rare. ${ }^{3,7,8}$ Abdominal trauma, sudden exertion, straining, and erosion of vessels by friction or pressure of the tumour against sacral promontory are few of its predisposing factors. ${ }^{2}$ In the above discussed case, the patient was unaware of mass in her abdomen and thus seeked medical attention in view of abdominal pain.

On examination, a large mass was noted, which on bedside ultrasonography, was diagnosed to be an ovarian mass (probably malignant) with ascites. The patient was stabilized, and posted for a CT scan to rule out metastasis. Ca 125 was borderline high. Few hours later when she vitally deteriorated, she was taken for an emergency laparotomy, only to reveal a large pedunculated, sub-serosal fibroid with massive haemoperitoneum from its ruptured superficial vein. The cause of rupture in this case could have been severe hypertension, or straining due to constipation. Malignancy was ruled out by intra-operative frozen section analysis, which reported benign leiomyoma. Panhystrectomy was performed in view of bilateral ovarian cyst. Four FFPs and four PCVs were transfused and patient was discharged uneventful in post-operative period.

This is an unusual presentation of a fibroid but has grave implications. In case review of 52 such cases, only 4 were correctly diagnosed and 3 died. ${ }^{4}$ Further, in a case report from 2016, a 29-year-old nulliparous female presented similarly, where myomectomy was performed to preserve future fertility. ${ }^{9}$ This suggests when large asymptomatic leiomyomas are diagnosed; a recommendation for removal should be made even in young females, as they are bound to enlarge during reproductive age.

They also have tendency of remaining asymptomatic, long before causing life-threatening complications and potentially even death. ${ }^{10}$ As surgical intervention is the only definitive treatment, all treating physicians must be aware of this rare complication.

\section{CONCLUSION}

Intra-peritoneal haemorrhage associated with uterine leiomyoma, is rare in spite of the fact the uterine 
leiomyomas are one of the most frequently encountered tumours. It usually presents with signs and symptoms of acute abdomen. Thus, causing confusion and delay in diagnosis. While a rare event, it may be life threatening and requires prompt surgical intervention, making it an important deferential that must be known by all emergency physicians while evaluating females with acute abdomen or sudden shock.

Funding: No funding sources

Conflict of interest: None declared

Ethical approval: The study was approved by the Institutional Ethics Committee

\section{REFERENCES}

1. Marshall LM, Spiegelman D, Barbieri RL, Goldman $\mathrm{MB}$, Manson JE, Colditz GA, et al. Variation in the incidence of uterine leiomyoma among premenopausal women by age and race. Obstet Gynecol. 1997;90:967-73.

2. Battery BW. Spontaneous haemoperitoneum complicating uterine fibromyoma. Aust N Z J Obstet Gynaecol. 1972;12:210-3.

3. Danikas D, Theodorou SJ, Kotrotsios J, Sills Cordero PE, Haemoperitoneium from spontaneous bleeding of a uterine leiomyoma: A case report Am Surg. 1999;65:1180-82.

4. Lotterman S. Massive hemoperitoneum resulting from spontaneous rupture of uterine leiomyoma. Am J Emerg Med. 2008;26:974.e1-2.
5. Shinde KK, Gavhane SP, Ghorpade N, Gupta K, Gangapurwala S. Massive hemoperitoneum due to rupture of surface veins of a uterine leiomyoma. Int $\mathbf{J}$ Biomed Adv Res. 2014;5(2):128-30.

6. Shapira A, Stars A. Massive intraperitoneal hemorrhage from ruptured subserous veins on the surface of uterine fibroid. $N$ Engl $J$ Med. 1932;207:827-9.

7. Manopunya M, Tongprasert F, Sukpan K, Tongsong T. Intra-leiomyoma massive hemorrhage after delivery. J Obstet Gynaecol Res. 2013;39:355-8.

8. Akahira J, Ito K, Nakamura R, Yajima A. Massive intraperitoneal hemorrhage and hypovolemic shock due to rupture of a coronary vessel of a uterine leiomyoma: a report of two cases. Tohoku J Exp Med. 1998;185(3):217-22.

9. Gulati N, Raman S, Srinivasan M, Bakour S. Rare gynaecological emergency: massive intraperitoneal haemorrhage from spontaneous rupture of a superficial vessel on a large leiomyoma. BMJ Case Rep. 2016.

10. Ihama Y, Miyazaki T, Fuke C. Haemoperitoneum due to rupture of a subserosal vein overlying a uterine leiomyoma. Am J Forensic Med Pathol. 2008;29(2):177-80.

Cite this article as: Jadeja YD, Shukla R, Vaishnav $\mathrm{S}$, Patel M. Massive hemoperitoneum in case of large subserosal fibroid- a rare case report. Int J Reprod Contracept Obstet Gynecol 2017;6:3185-7. 